\title{
LOS LÍMITES DE LA FRAGMENTACIÓN DEL RELATO EN CRUZ DE OLVIDO DE CARLOS CORTÉS
}

\author{
Shirley Montero Rodríguez
}

\begin{abstract}
RESUMEN
El presente trabajo procura establecer la propuesta teórica de la paratextualidad, como una herramienta importante en el acercamiento crítico al texto de ficción. Para ello, se analizan los principales paratextos de la novela Cruz de olvido, del escritor costarricense Carlos Cortés, con la intención de establecer esa propuesta inicial de ruptura, que orienta la lectura total del texto literario.

Palabras clave: paratextualidad, epígrafes, título, íncipit/cuadro-final, narrativa costarricense, Carlos Cortés.
\end{abstract}

\begin{abstract}
The present work means to establish the theoretical offer of the paratexts as an important tool in the critical approximation to fiction text. For this, the principal paratexts of the novel Cruz de olvido of the Costa Rican writer Carlos Cortés are analyzed, this with the intention of establishing the initial proposal of break out, which orientates the entire reading of the literary text.

Key words: paratexts, epigraphs, title, inicial frame/final frame, Costa Rica narrative, Carlos Cortés.
\end{abstract}

\section{Introducción}

Es indispensable recordar la afirmación de Genette, cuando indica que se debe considerar la transtextualidad y sus componentes (intertextualidad, paratextualidad y otros) en general, no como una clase de textos sino como aspectos de la textualidad (literariedad), ya que todo texto posee trascendencia textual (1989: 18). En este sentido, los paratextos son esos aspectos que trascienden el texto literario, pues poseen una carga semántica que relaciona al texto con "algo más" y que sirve de límites, de anticipación y de orientación a la lectura. Los espacios preliminares a todo texto literario

Shirley Montero Rodríguez. Master Literarum en Literatura Latinoamericana. Profesora de Literatura, Coordinadora de la Sección de Filología en la Sede de Occidente, Universidad de Costa Rica.

Correo electrónico: shirleymr02@costarricense.cr

Recepción: 23- 11- 2008

Aceptación: 18- 2- 2009 
se han denominado, entonces, como paratextos. Son aquellos textos paralelos al texto literario, los cuales le son autónomos mas no independientes, y resultan fundamentales para la comprensión de la producción ficcional.

Gerárd Genette denomina a los paratextos de la siguiente forma: "Le paratexte est done pour nous ce par quoi un texte se fait livre et se propose comme tel à ses lecteurs, et plus genéralement au public. Plus que d'une frontière éche, il s'agit ici d'u seuil..." (1987: 7). Este teórico francés ubica dentro de la paratextualidad elementos como: título, subtítulos, intertítulos, prefacios, epílogos, advertencias, prólogos, notas al margen, al pie de página, epígrafes, ilustraciones, fajas, sobrecubierta, etc. Son todas aquellas señales accesorias que forman parte del entorno del texto literario, y que se constituyen en uno de los sitios privilegiados para la dimensión pragmática, o sea, en la acción sobre el lector y el contrato de lectura consecuente (Genette 1989: 11- 12).

A pesar de la pluralidad de posibilidades que involucra la paratextualidad, cuatro de estos espacios fronterizos al texto son valiosos para la presente lectura: los epígrafes, el título principal, el cuadro inicial o íncipit y el cuadro final. La novela Cruz de olvido es una ácida e inquietante red textual de significaciones finiseculares sobre la Costa Rica desencantada y desesperanzada de fines del siglo XX. ¿Explicitan estos textos preliminares el discurso de la crisis identitaria? Ante esta interrogante, se debe recordar que el texto literario es un proceso comunicativo en su totalidad, por lo cual las condiciones de la enunciación: “...se instituyen en el acto mismo de escritura y se materializan en un lugar estratégico por excelencia, el paratexto o espacio liminar, en el cual se manifiesta, con mayor fuerza, esa dimensión ilocutiva del lenguaje al dirigir la comprensión hermenéutica del texto" (Chen 1997: 301).

\section{Ecos de la ruptura: Los epígrafes}

Los epígrafes se consideran algo más que simples citaciones de un determinado autor y su obra. En realidad, son entendidos como elementos que justifican, esclarecen o adelantan comentarios sobre el texto literario mismo (Genette 1987: 145). Asimismo, sirven para obtener la eventual decodificación del texto como signo, de manera que van más allá de su relación con el cuerpo de la novela y su mayor importancia radica en la oportunidad que proporcionan para explicar el texto literario como un todo (Genette 1987: 145-146).

En este sentido, los tres epígrafes que inician la lectura de Cruz de olvido han de responder a estas funciones básicas. No obstante, dan asomo de alguna significación más, ya que son lo que Genette denomina epígrafes nominados, es decir, contienen el autor al cual le son atribuidos (1987: 142- 143).

Los tres epígrafes nominados sirven a la novela como refuerzo de autoridad, introduciendo de antemano una significación de validez a través de la institucionalidad literaria. Lo que cada uno de estos paratextos indica, tendrá entonces relación con el cuerpo de la novela, pero, a la vez, posee un referente extratextual para su admisión, por ende, un significado mayor con respecto al signo-texto.

El primer epígrafe pertenece a la literatura griega clásica y refiere al texto epopéyico La Odisea. La cita se ubica en la segunda rapsodia, "Ágora de los itacenses.-Partida de Telémaco" y son palabras enunciadas por el mismo Telémaco:

...vivo o muerto, en la Tierra se encuentra mi padre... Males de mi padre sufriré, y han de darme los dioses otros más; a imprecar se pondrá a las odiosas Erinies... y caerá sobre mí la condena de los hombres... 
En la búsqueda del padre, la telemaquía indica un viaje del individuo para recuperar su origen. Es un recorrido para encontrar respuesta(s) a la interrogante inicial de ¿quién soy? Las relaciones de parentesco, que marcan tanto a la novela como al epígrafe, indican una búsqueda de identidad, la cual es producto de una crisis-crítica-reflexión sobre la propia existencia. El castigo de dioses y de humanos, la condena, los males, como herencia malsana, dan a la paternidad un tinte de ruptura y caos en el sujeto enunciador: Telémaco, Martín Amador, Jaime.

El segundo epígrafe pertenece a un periodista y escritor austriaco, quien vivió a inicios del siglo XX, durante el declive de su patria debido a la absorción que esta sufriera por parte de Alemania y a raíz del Anschluss en 1938, donde Austria pasó a formar parte del Reich hasta 1945. Reza lo siguiente:

La alegría de haber bregado por una gran idea sigue determinando nuestra conducta mucho después de
que la duda nos haya vuelto lúcidos, conscientes y desesperanzados.

Aquí, Roth ${ }^{1}$ destaca los grandes ideales como forma de evadir una realidad desalentadora e introduce el término $d u d a$ para reconocer la crisis-crítica a manera de mecanismo de reflexión y conocimiento de dicha realidad. Pone de manifiesto cómo la ilusión del ser humano radica en una negación de lo evidente-desesperanzador, ante la duda dolorosa la quimera es el aliciente.

Por último, el tercer epígrafe corresponde a Francis Scott Fitzgerald²:

Toda vida es un proceso de demolición.

F. Scott Fitzgerald

Este escritor norteamericano junto a John Roderigo Dos Passos, Ernest Hemingway, Edward Estlin Cummings y Gertrude Stein, formó la denominada "generación perdida", grupo de jóvenes escritores, los cuales tras la desesperanza intelectual de la Primera Guerra Mundial buscaron escapatoria de diversas formas: sus viajes, el socialismo y, sobre todo, la literatura.

Los tres epígrafes poseen una doble referencialidad con respecto a Cruz de olvido. Hay una primera asociación de carácter exógeno, la cual remite a una época de crisis, pues los escritores enunciados encarnan la imagen de la evaluación de sus propias circunstancias contextuales.

Homero reflexiona en torno a la idealización de los valores heroicos anteriores a su presente. Roth y Scott Fitzgerald vivieron y sufrieron la transición hacia el siglo XX, quizás uno de los más sangrientos que ha vivido la humanidad, recrudecido con dos guerras mundiales, la primera detonación de una bomba atómica, múltiples revoluciones y guerras civiles. El perfeccionamiento del instrumental bélico, la violencia del hombre por el hombre, marcan a sociedades que se vuelven convulsas y caóticas. Esto es precisamente lo que evidencian los epígrafes de estos escritores quienes, como Cortés, apuestan por la evaluación reflexiva, ante un período finisecular de incertidumbre. Así, con casi cien años de distancia entre los textos de Roth y Scott Fitzgerald y la producción ficcional de Carlos Cortés, este último se devuelve para hacer un reconocimiento del impulso de transición de un siglo a otro y el devenir que prefigura cada vez menos como destino o progreso.

En esta primera mirada exógena que proporcionan los epígrafes, el escritor asienta las bases del contexto sobre el cual pretende referir su palabra, un momento de caos-crisis-crítica y, finalmente, reflexión ante sus propias circunstancias.

Una segunda asociación de carácter endógeno de estos paratextos, remite al espacio subjetivo. Los tres epígrafes entroncan en el interior del sujeto, el cual asume estas circunstancias caóticas de su contexto e inicia el proceso de crisis-crítica. 
El epígrafe homérico alude a la reflexión primigenia del ser humano con respecto a su origen paterno -propio de una sociedad patriarcal- donde los lazos de parentesco se vuelven una herencia maldita, en idéntica referencia a Martín Amador y su hijo Jaime o, quizás, la constitución metafísica de la identidad nacional y los discursos identitarios de la sociedad costarricense de fin de siglo XX e inicios del siglo XXI.

La voz del sujeto, tanto en los epígrafes como en Cruz de olvido, se vuelve no solo crítica, sino amarga y desesperanzada. Joseph Roth habla de la ilusión de un gran ideal muerto, punto al que llega el protagonista (Martín Amador) de una sociedad sin ideales (la costarricense) en Cruz de olvido. Y en ese instante de desaliento, el epígrafe de Scott Fitzgerald habla de la vida como "proceso de demolición”. Así, para construir, Martín Amador primero debe demoler. En este aspecto, el sujeto de esta contemplación endógena, es un sujeto fragmentado entre su herencia, lo que fue, lo que posee y lo que será. Es un sujeto que evalúa las referencias de su contexto, por ende, entra en crisis. Su voz, su discurso, se configuran en la segmentación de esa transición finisecular, que se devela como un proceso especular donde el individuo mira su interior para luego mirar el exterior, la cual posibilita una metamorfosis íntima en su relación con los discursos sociales circundantes.

¿Quién soy?, ¿de dónde vengo?, ¿a dónde voy? Son interrogantes fundamentales para un sujeto, sea individual como Martín Amador, Carlos Cortés, Scott Fitzgerald, Joseph Roth u Homero, o colectivo, como la sociedad costarricense finisecular. Ante estas interrogantes, el sujeto se vuelve reflexivo sobre su principio fundamental de pertenencia, de identificación y entra en crisis.

Estos paratextos iniciales evidencian una relación directa con la novela en cuestión, pues justifican y adelantan no solo temática relacionada con la diégesis, sino con respecto a un punto relevante: la cuestión identitaria. Ante la pregunta esencial ¿quién soy?, la conciencia del ser humano busca permanentemente una respuesta vital, la identidad, en un marco existencial dotado de adversidad y desilusión. De tal manera que las delineaciones de la crisis quedan asentadas.

\section{Sobre el título de la novela}

La denominación primera de un texto literario marcará su existencia en el mundo de las concreciones. A raíz de ello el título de la novela es un elemento fundamental en la estructuración del significado de la misma: "L'identification est, dans la practique, la plus importante fonction du titre, qui pourrait à la rigueur se passer de toutes les autres" (Genette 1987: 77).

Según Amalia Chaverri, para Leo Hoek todo título está constituido por cuatro componentes básicos: sintáctico, semántico, sigmático y pragmático; los dos componentes iniciales tienen total independencia del cuerpo de la novela intitulada; y los otros dos indican su relación con la diégesis (1997: 39- 41).

Además, Genette apunta que: “...los títulos de las obras -literarias o no- no forman una clase de enunciados amorfa, arbitraria, intemporal e insignificante” (1989: 50). Bajo este entendido, “...el título ayuda al lector a orientar su actividad de decodificación. El título funciona de manera metonímica: la parte permite citar el todo" (Amoretti 1983: 149). Entonces, ¿qué es ese todo que cita Cruz de olvido? 


\subsection{Rasgos sintácticos y semánticos del título}

En primera instancia, el elemento que más llama la atención del lector es el título mismo de la novela. Este elemento liminar está constituido, desde la perspectiva sintáctica, por dos estructuras: cruz es un sustantivo concreto-común-individual, y olvido es un sustantivo abstracto de idea (creación de una denominación para algo que no es aprehensible por los cinco sentidos biológicos del ser humano). Estas dos palabras están unidas mediante la preposición de que indica pertenencia, y forman un grupo nominal donde el primer sustantivo cumple la función de núcleo, por tanto, posee la mayor fuerza de significación; en tanto que el segundo aparece en función de término, o función preposicional, convirtiéndose en adjetivo del primero.

Igualmente, es interesante observar la carencia de artículo en esta estructura gramatical. Quizá se deba a que ese elemento morfológico limitaría la significación del enunciado. En tanto que sin el artículo, semánticamente, cruz remite a cierta relacionalidad diferencial, donde no se puede encasillar en límites determinados. Asimismo, la carencia de artículo, proporciona al enunciado un carácter abstracto, el cual genera una expansión de su significado.

Consecuentemente, desde la perspectiva semántica, el grupo nominal Cruz de olvido adquiere una carga significativa que concede abrir un panorama previo de entendimiento al texto.

El término cruz (el de mayor fuerza), etimológicamente proviene del latín crŭx, crŭcis, cuyo significado es horca, picota, tormento, pena, azote (Corominas 1974: 420), indica la crucifixión de Cristo y su agonía, dolor y sufrimiento. Cruz, como elemento limitado a lo latinoamericano, se une con otro sustantivo: la espada. La cruz y la espada fueron los símbolos opresores y represores de la conquista europea en América Latina. El primero, usado por la iglesia católica como elemento de conversión, remite al nivel ético-moral, pero propenso de ser cuestionado ante las graves faltas humanas que implicó el proceso inquisidor. El segundo, símbolo del poder impuesto, lo político. Ambos elementos, cruz y espada, respondían a un mismo propósito (dominar) y proyectaban el Centro hacia este margen latinoamericano, espejo de sus monstruos interiores, imaginario de sus miedos, paradójica utopía concreta, como concreto es el sustantivo: “...debemos colocar en primer lugar el papel que el milenarismo tuvo en la conquista y evangelización del Nuevo Mundo. La Cruz y la espada, puede decirse, proyectaron la misma sombra sobre el nuevo continente" (Mendieta 1998: 244).

Olvido, del latín oblivium, indica falta de memoria, lo cual establece una oposición entre memoria y olvido, que a su vez remite al binomio presente/pasado (Diccionario Pequeño Larousse Ilustrado 2002: 737). Mendieta escribe sobre este término: “...a nuestro olvido del Ser corresponde nuestro olvido del tiempo" (1998: 238). Dentro de la novela, es el olvido del ser identitario, la anulación del sujeto individual y colectivo (pueblo) como participante y portador de voz, el que calla, tolera, o ignora negligentemente. También, es el olvido del tiempo, cárcel de opresión social que la traemos atada al brazo, como metáfora cortazareana. Es el olvido del nosotros-periféricos y oprimidos, bajo una doble abstracción: olvido-tiempo. Por lo tanto, Cruz de olvido correspondería a un indicador de una carga de sufrimiento ligada con el tiempo pasado y presente, circunscrito como un operador temporal.

El título de la novela transmite una asociación con un principio, un génesis:

La cruz se ofrece como una derivación dramática, como inversión del árbol de la vida paradisíaco. Por ello, en la iconografía medieval, la cruz es representada muchas veces como árbol con nudos y hasta con ramas [...] Cual acontece con el árbol de la vida la cruz es un eje del mundo situado en el centro místico del cosmos, es el puente o la escalera por la que las almas suben hacia Dios [...] relación primaria entre dos mundos (terrestre y celeste) (Cirlot 1969: 162). 
Adquiere así, rasgos semánticos de un operador espacial, como lo es la expulsión del paraíso terrenal, y el inicio del sufrimiento y el castigo humanos, en la ubicación de un valle de lágrimas y penas. Es, en realidad, una forma de recurrir al origen mítico del ser humano, atribución de una característica antropocéntrica fundamental.

Desde las perspectivas sintáctica y semántica, el título principal de la novela se inscribe, según Amalia Chaverri, como operador objetal al aludir a un ente inanimado (1987: 36- 37), sin embargo, sufre una resemantización que lo convierte en un operador actancial. Cruz de olvido se transforma en el elemento protagónico del texto literario, marca el inicio de la novela y guía la lectura total. De hecho, en el título se realiza el procedimiento retórico señalado como figura literaria de personificación, donde el objeto inanimado adquiere rasgos de sujeto y pasa a convertirse en el actante fundamental de la novela.

\subsection{Acercamiento sigmático: El título y el cuerpo novelar}

El campo sigmático del título debe ser entendido como la relación título-cuerpo de la novela, pero además involucra: "Las relaciones entre el signo de la práctica significante dada y los objetos a los cuales remite. Es el estudio del referido, entidad correspondiente, pero propia de un mundo posible, en otras palabras, la extensión del enunciado..." (Chaverri 1991: 22).

La relación del título con el cuerpo de la novela se observa primero en el índice, capítulo V con la misma denominación. El capítulo denominado "Cruz de olvido" clarifica en gran medida la connotación del título principal, pues alude al enfrentamiento del protagonista, Martín Amador, con su pasado y el olvido al que pretendió desterrarlo: "Realmente ahora me daba cuenta que el hijo de mi ex mujer era también mi hijo, aunque formara parte del último cajón de mis recuerdos [...] Mi vida personal se había borrado de cualquier tipo de atadura" (Cortés 2000: 70).

El peso psicológico de este yo (la cruz que debe afrontar) está marcado por el reconocimiento de su pertenencia, encarnada en los nexos familiares, es decir, por un olvido que no logra aprehender: "La información ofrecía los mismos datos que ya conozco, que he conocido siempre, que he tratado de olvidar y que he recobrado después de años de olvidos, de anticipados olvidos. Después de todo sólo tengo la memoria. La memoria y la culpa. Pero uno aprende a vivir con la memoria y con la culpa" (Cortés 2000: 72- 73).

El olvido que no consigue Martín Amador es desplazado mediante la memoria y la culpa, de ahí el simbolismo del entierro de Jaime, al que asiste el protagonista: "Más de 20 años después Jaime repetía mis pasos pero en sentido contrario" (Cortés 2000: 76). Este yo debe enterrar la evasión, retornar a su origen, como Odiseo, y enfrentarse a su sino vital, ahora perpetuado, en su único hijo crucificado en la Cruz de Alajuelita.

Este significativo capítulo V, además, brinda al título una doble referencialidad. En primera instancia, el planteamiento de un asesinato en La Cruz de Alajuelita, en San José, referente locativo que afianza lo sigmático del título principal de la novela. Esto se ve reforzado en la descripción del discurso periodístico sobre asesinatos, y recuerda particularmente el ocurrido el 6 de abril de 1986, donde siete mujeres, algunas de ellas niñas, fueron brutalmente asesinadas:

El periódico ofrecía tres o cuatro páginas de información sobre la matanza, un croquis de toda el área del crimen y un mapa de la zona montañosa de Alajuelita y estribaciones. Un reportaje central mencionaba las indagaciones más o menos sistemáticas de la Dirección de Investigaciones Criminales (DIC) (Cortés 2000: 72). 
En segundo término, se realiza una relacionalidad del título con una canción popular de corte romántico y melancólico, del mexicano Juan Zaizar, la cual lleva la misma titulación, e igualmente aparece en el capítulo $\mathrm{V}$ de la novela. Dicha canción popular mexicana se representa como un mensaje de un yo-destinador-amante, quien justifica su partida a un túdestinatario-amada, por lo cual toma como núcleo significante el viaje-abandono (en idéntica asociación con el primer epígrafe de la novela), es decir, un desplazamiento espacial (viaje en una barca que ha de llevar una cruz de olvido) del yo de la canción que produce la analogía: olvido $=$ amor $=$ dolor .

El doble referente del título de la novela, en el aspecto sigmático, corrobora el canon de dolor de la cruz. Elemento purificador por excelencia, desde la perspectiva humana espiritual, ya que produce una destrucción que reconstruye (Apocalipsis-Génesis), y el tercer epígrafe de la novela lo representa en la vida misma del protagonista, Martín Amador. Visión de la posmodernidad, de la crisis personal, del caos, como evaluación de lo vivido.

La cruz es una conjunción de contrarios, donde se unen el principio espiritualverticalidad y la manifestación de la tierra-horizontalidad, dentro del orden racional, de ahí su sentido agónico, como lucha o como instrumento de martirio. Sin embargo, el martirio de Martín Amador no es el olvido, sino el querer olvidar el pasado (historia) y no poder hacerlo; es decir, el martirio es la memoria (linealidad) que le impide reconstruir su vida, pues el tiempo es el que codifica y reglamenta toda la vida individual, social e histórica.

Estar crucificado, como el protagonista de la novela, es vivir la esencia del antagonismo, base que constituye la existencia, su dolor agónico, su cruce de posibilidades y de imposibilidades, de construcción y destrucción. Esa intersección de elementos contrarios representa la novela a partir de los binomios: memoria/olvido, presente/pasado, antes/ahora, público/privado, destrucción/construcción. Se representa por medio de las líneas que estructuran la cruz en forma muy similar a un plano cartesiano, signo de la razón de la modernidad:

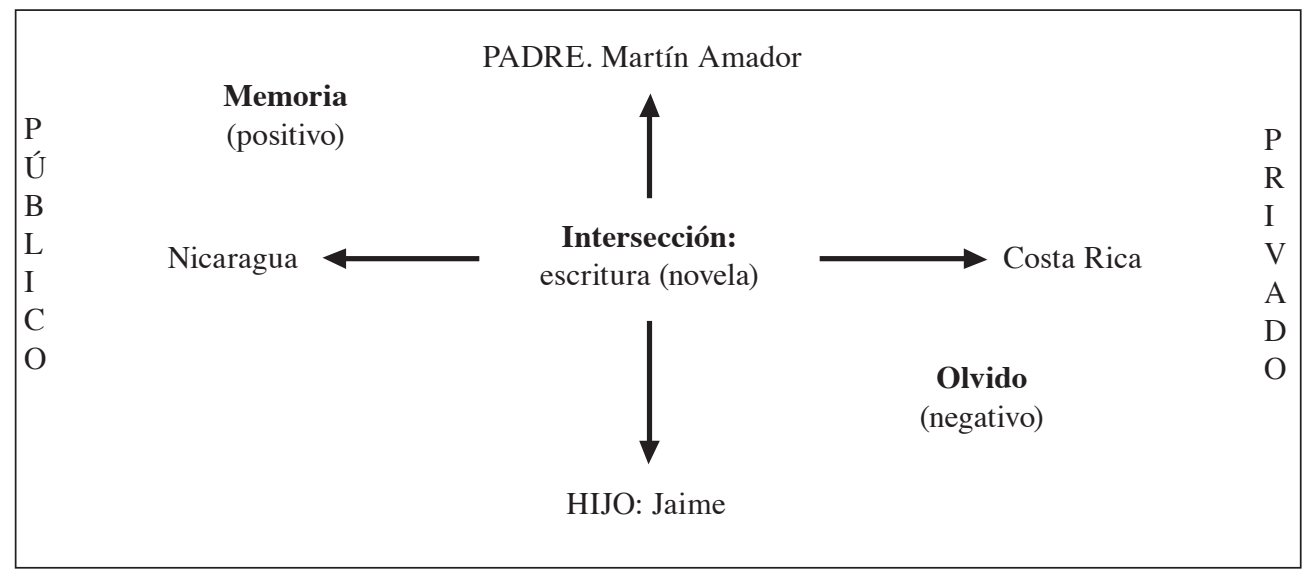

Figura 1. La cruz como plano cartesiano de la modernidad, en el título de Cruz de olvido

En esta representación observamos las dos líneas que se intersecan en la novela: por un lado el plano de la linealidad histórica, establecida mediante coordenadas espacio-temporales a partir de la vida del protagonista (Martín Amador) entre Costa Rica y Nicaragua, y su trabajo como periodista en ambos sitios. El eje horizontal corresponde a lo terrestre, o lo público, lo que se ve, a la memoria que no atormenta, porque es olvido. En segunda instancia, se presenta 
el plano de lo emocional-fragmentario, las relaciones familiares del protagonista, el hijo que no conoce, la carencia del padre, la madre abandonada. Es el eje vertical, e incumbe a lo íntimoprivado, corresponde al dolor y la culpa, es decir a lo olvidado que se debe ver como negativo.

Cruz de olvido se constituye en un enunciado que programa y dicta las pautas esenciales para hacer el recorrido de una historia fragmentaria, convulsa, especular y contradictoria, que abre la crisis identitaria del sujeto a partir de una óptica particular, la del escritor que lo propone y la del lector que la desentraña. La cruz es el elemento que abre y cierra este enunciado llamado novela.

\title{
4. Los conjuntos - límite de la novela
}

Roland Barthes entiende la novela como un sistema de códigos múltiples y simultáneos, y ante la interrogante ¿por dónde empezar?, él habla de establecer primero los conjuntos límite: inicial y terminal, para explorar después cómo el segundo se une al primero o se diferencia de él. A estos conjuntos límite, el teórico francés ha denominado como cuadros: “...vasto concurso inmóvil de datos iniciales [...] Para parar el cuadro inicial, no existe, a partir de este momento, más que un solo medio: ayudarse dialécticamente con el cuadro final (o recíprocamente, según los casos)" (1974: 60- 61).

En este sentido, el cuadro inicial y el cuadro final pasan a formar parte importante del texto literario, puesto que sirven en el desentrañamiento de su comprensión final como signo, a la vez que posibilitan una forma de inicio en la hermenéutica de la crítica literaria. Consecuentemente, la pluralidad del texto literario proporciona la posibilidad de hilvanardeshilvanar su múltiple red de significaciones por cualquier hilo conductor de sentido, y en el caso de Cruz de olvido, tanto el cuadro inicial como el cuadro final brindan esa oportunidad de lectura, ya que:

\begin{abstract}
...no es posible comenzar el análisis de un texto [...] sin adoptar una primera visión semántica (de contenido) [...] El trabajo que entonces nos queda por hacer (inmenso) consiste en seguir los primeros códigos [...] pero igualmente proponer otros códigos, que vienen a perfilarse en la perspectiva de los primeros (Barthes 1974: 69- 70).
\end{abstract}

\section{1. $\quad$ El cuadro inicial de la novela o íncipit}

Aunado al concepto anterior de cuadro inicial, María Amoretti Hurtado habla de este como el íncipit de la novela (del latín incipio, comienzo) y apunta: “...el comienzo de un texto es un lugar estratégico de condensación de sentido. Desde el arranque, el texto organiza una serie de códigos que pueden orientar la lectura crítica [...] lanza las huellas de un trabajo textual productor de ideología y, al ser la iniciativa de la palabra, fija sus presuposiciones y jurisdicciones" (1992: 66- 67). En consecuencia, la primera frase de un texto establece la relación afuera-adentro, ya que elige del mundo sus propios materiales de partida, el espacio, el trayecto y la lectura del texto y tal como lo indica María Amoretti: “...orienta [...] la lectura del relato, su legibilidad, concatenando sus elementos primordiales, es una 'decisión"' (1983: 145-146), de ahí su vital importancia.

Con el entendido anterior, para efectos de la presente lectura se tendrá como cuadro inicial o íncipit de la novela la frase inicial y los siguientes tres párrafos, los cuales dicen así:

En Costa Rica no pasa nada desde el Big Bang", me dijiste.

Había estado rumiando y escupiendo aquella frase mientras cargaba y descargaba mi viejo jeep Willis con diez años de Revolución sandinista cuando recibí una llamada telefónica que me cambió la vida, como no 
lo había hecho antes ni siquiera la insurrección, ni el amor, ni quizá la muerte.

Siempre había creído vivir antes de la historia, en sus márgenes, en la esquina más alejada de Occidente, en la periferia del mundo. O al menos lo había intentado. Y una llamada telefónica del Panameño lo cambió todo.

Mi hijo Jaime, de 18 años, y seis compañeros más, habían aparecido aquella mañana crucificados, decapitados y mutilados en La Cruz de Alajuelita, una inmensa cruz de metal que domina la ciudad de San José desde una estribación montañosa. El siete siempre ha sido mi número preferido. La cábala de mi maldito destino (Cortés 2000: 13).

Lo primero que llama la atención de este íncipit es su presentación por medio de una confesión, donde un yo se dirige a un tú familiar y conocido. Por medio de esta apelación directa del narrador-protagonista al lector, se establece un contrato de confianza, tal como lo establece Greimas: "...un creer-verdad debe instalarse en los dos extremos del canal de la comunicación y a este equilibrio más o menos estable, a este entendimiento tácito de dos cómplices más o menos conscientes, lo denominamos contrato de veridicción (o contrato enuncivo)" (Greimas y Courtés 1990: 432). Con dicho contrato se pretende hacer partícipe y cómplice de la novela al lector, por lo cual los lazos que unen lo interior del texto con lo exterior se destensan, de tal forma que se genera una transición entre lo extratextual y lo intertextual.

Este sintagma se centra en el personaje principal y los acontecimientos que lo rodean, ya que el inicio resume los puntos más importantes del relato. De tal manera, en este espacio liminar se responde a las preguntas ¿qué?, ¿dónde? y ¿cuándo? (Amoretti 1992: 66). Un participante de la Revolución sandinista cuenta su propia historia; está en Nicaragua preparándose para su regreso obligado a Costa Rica, debido a la noticia donde se le informa que su hijo fue asesinado en La Cruz de Alajuelita.

De esta manera, la novela alude a un doble fracaso en cuanto al detrimento de los ideales, a partir del personaje de Martín Amador. En este se observa el desengaño del proyecto socialista en América Latina y, particularmente, en Centroamérica, al aludir a la pérdida de poder del gobierno sandinista y consecuentemente, en 1990, el gane de las elecciones por parte de Violeta Chamorro. Con este elemento referencial se unifica el fracaso de los ideales políticos socialistas de los años setenta y el fracaso personal del protagonista, lo cual genera una pérdida de fe y la instauración de la desesperanza.

Además de ubicar al lector en cuanto a los lineamientos generales de la narración, este íncipit proporciona una serie de indicios y símbolos fundamentales para el entendimiento total de la estructura significante de la novela.

El yo adquiere rasgos zoomórficos (rumiando y escupiendo), como símil ideal para plantear su carácter estacionario y pasivo; pero detona en su vida una llamada telefónica, tal como la primera frase del íncipit donde el Big Bang, la gran explosión cósmica que dio origen a la vida. Pasividad/actividad se contraponen directamente en el relato, como lo hacen estaticidad/movimiento. "En Costa Rica no pasa nada desde el Big Bang” y en su vida tampoco ocurría nada antes de esa llamada.

Sobre el número siete, Cirlot dice que la septuplicidad se constituye en la integración del espacio y el tiempo, como forma que retiene y a la vez destruye el libre movimiento (1969: 164). Surge de nuevo la bipartición de los opuestos, destrucción/construcción (dicho de otra manera vida/muerte). Pero, es una destrucción mucho más profunda que la eliminación de la vida, o el asesinato mismo y que se liga a la cruz como elemento de suplicio corporal y psicológico, una cruz que domina, en asociación directa con los epígrafes y el título de la novela. 
El número siete, se retoma a lo largo del relato: siete víctimas del crimen; el sobrenombre del principal conspirador contra Martín Amador, Edgar Jiménez conocido como Siete Puñales; el número de cuenta del protagonista, razón misma de la trampa, que como dice después Ricardo Blanco “Un número de 'siete cifras', ¿eso es lo que están buscando? ¿Están buscando el número en Suiza donde supuestamente está la plata de los gringos que había que repartir después de lo de Nicaragua ¿Por eso vino Martín Amador? ¿Y por eso le secuestraron al carajillo?" (2000: 217); el nombre de la hermosa mansión de principios de siglo que había pertenecido al artista Ricardo Pacheco, "La casa de los siete ahorcados"; o las siete puertas de la Casa Presidencial, donde se resolvía el destino del país. Este número se repite a lo largo de la novela con un significado muy cercano a la cruz, como unión de opuestos, sobre todo en los lineamientos del espacio-tiempo, o construcción-destrucción (Cirlot 1969: 164). De ahí también su similitud con la culpa-castigo y el olvido-aliciente.

El siete y la cruz son la cábala de un destino marcado por el martirio, aunque el narrador no puede evitar su camino, este último está trazado, porque él así lo eligió o prefirió: "El siete siempre ha sido mi número preferido". ¿Elección o azar?, discurso ambivalente de nuevo, como el de quien esconde algo. Camino trazado por la modernidad, mediante la razón, el tiempo y el espacio como marcas opresoras. La superposición del espacio y el tiempo, se constituyen en una especie de cronotopo que retiene y destruye el libre movimiento del yo.

\subsubsection{Las coordenadas temporales narrativas}

Los verbos del íncipit se dividen, por parte del narrador, en dos tiempos fundamentales: pretérito perfecto e imperfecto del modo indicativo (dijiste, había estado, cargaba, descargaba, recibí, cambió, había creído, había intentado, cambió, habían aparecido, ha sido) y el presente (pasa, domina). Esto establece un nexo indisoluble entre el binomio presente/pasado en torno al cual girará, simultáneamente, todo el relato. Por consiguiente, es un yo que a pesar de estar en el presente continúa atado y recordando un pasado que revive a cada paso de su narración. Presente/pasado son las líneas temporales que se acercan, se alejan, se tensan y destensan a lo largo de la novela de Carlos Cortés.

Unida a esa percepción temporal, se presenta otra bipolaridad, historia/evasión, como una contradicción por parte del narrador. Este protagonista, cuando indica su intento por vivir en los márgenes de la historia, en su periferia, trata de evadir su participación directa; sin embargo, asevera haber participado de la Revolución sandinista durante diez años. El yo pretende constituirse como un ser marginal, pero su discurso es ambivalente, ¿se trata acaso de un individuo ambiguo o fragmentario?

La llamada telefónica que recibe el yo marca un desplazamiento temporal, donde va de su presente a su pasado, es decir del olvido a la memoria, lo cual genera una connotación de sufrimiento y agonía: “...mi maldito destino”.

Según Eduardo Mendieta: “...como estructuración temporal de la vida social realizada a través del régimen temporal del Estado y el mercado, la modernidad es un panóptico temporal [...] Su eficiencia deriva de los modos en que virtualiza y autonomiza el poder" (1998: 247). El regreso marca el desplazamiento temporal que sufre el sujeto, pero a la vez indica un ejercicio del poder, pues no se trata de un libre deseo, sino de un retorno obligado. 


\subsubsection{Las coordenadas espaciales narrativas}

Del latín spatium, se entiende por espacio el continente de todos los objetos sensibles que coexisten, capacidad de terreno, sitio o lugar; no obstante, también se define como el transcurso del tiempo (Diccionario de la Real Academia de la Lengua Española 1984: 567). En este sentido, las coordenadas espaciales que se inscriben en el íncipit de la novela, permiten una interdependencia con respecto a las coordenadas temporales, lo cual inscribe un punto de encuentro o vértice semántico de lectura.

Al igual que las coordenadas temporales, las coordenadas espaciales que se observan en el íncipit de la novela marcan una duplicidad de puntos opuestos en su semántica, lo cual da origen a un binarismo evidente: Costa Rica y Nicaragua.

Nicaragua está significada a través del movimiento, la Revolución sandinista, es la inconformidad y el cambio permanente. Dicha transmutación constante no se observa en Costa Rica, la cual por el contrario es estática y donde “... no ocurre nada desde el Big-bang” (Cortés 2000: 13).

La representación de planos cartográficos y psicológicos opuestos se denota mediante otras analogías. Así por ejemplo, Nicaragua es el "margen", "la esquina de Occidente", pero al ser transformación es insurrección de la periferia, y es la libertad del individuo que se opone al dominio del centro-poder. No obstante, Costa Rica aparece simbolizada bajo la cruz de metal en una estribación montañosa, a través de su capital-centro-poder San José; por ende, es dominio y coacción sobre el sujeto. Para el yo el centro-opresor está en Costa Rica y la periferia-liberadora es Nicaragua.

La libertad del sujeto radica precisamente en la posibilidad de sublevarse contra la opresión de que es objeto, es decir la posibilidad de acceder a su condición de sujeto. De la misma forma, el margen o periferia es la posibilidad del anonimato, el escondite perfecto para huir de su interioridad, ya que es el espacio público. Pertenecer al grupo o colectivo social aminora las responsabilidades y crea el sitio adecuado para la anulación del sujeto, por lo cual es una falsa huida y el olvido no se produce en su totalidad.

El regreso al centro es la existencia del sujeto ya no como parte del espacio público, sino dentro del espacio privado y en sus relaciones de parentesco, es la nominación de la individualidad del narrador que lo obliga al retorno y al enfrentamiento interno, es la memoria.

El elemento que une a los dos espacios narrativos del íncipit, centro-periferia y público-privado, es la violencia, tanto de la Revolución sandinista como del crimen de La Cruz de Alajuelita, pero recrudecido bajo la connotación del castigo-crucifixión-decapitaciónmutilación que produce el centro-opresor.

La oposición huida-regreso implica un desplazamiento espacial del sujeto, la cual remite intertextualmente a La Odisea homérica, en asociación con el primer epígrafe de la novela. Dicho desplazamiento es una representación de la telemaquía, pero en sentido inverso, ya que es la visión del padre y no del hijo, es decir se narrará la otra parte de la historia, que a la vez puede ser la misma. A partir del primer epígrafe y el íncipit se produce una especie de diálogo, en uno la voz del hijo-Telémaco-Jaime ejecuta un llamado sobre su castigo y en el íncipit la voz del padre-Odiseo-Martín inicia su viaje.

El regreso a Costa Rica, como Ítaca, involucra un enfrentamiento del yo en contra de sus adversarios, tanto materiales como psicológicos. El padre debe regresar por su hijo, quien ha de pagar las culpas paternas, es la herencia maldita que conlleva el castigo. La periferia, Nicaragua, es la multiplicidad de aventuras aturdidoras y evasivas de las no deseadas circunstancias de vida del yo. 
Los lazos consanguíneos padre-hijo marcan el regreso, pero también el martirio de la cruz. Símbolo mesiánico, el padre entrega a su único hijo, pero luego lo reclama. No obstante, el hijo (Jaime) paga por los pecados de su padre y esto debe servir para redimirlo. Es en realidad una búsqueda interior, un cruento enfrentamiento de la mismidad que atormenta al punto de desear el olvido como aliciente a la culpabilidad.

En consecuencia, el desplazamiento espacial que debe afrontar el yo va más allá de lo locativo. Atisba tanto la geografía externa (Nicaragua-Costa Rica) como interna (públicoprivado) del sujeto y lo obliga a asumir una cuarta pregunta fundamental en la lectura del íncipit: ¿quién? Esta referencia esencial alude a la cuestión identitaria a partir de la situación social, familiar y personal del sujeto. ¿Quién soy frente a mí mismo y frente a los demás?, ese es el núcleo semántico que orienta la lectura del texto a partir de su íncipit.

Finalmente, ambos desplazamientos (temporal y espacial) involucran una significación aumentada, pues el símbolo del viaje personal linda en una martirizante e inevitable búsqueda de la propia identidad. El íncipit presenta las interrogantes básicas: ¿Dónde?, Nicaragua/Costa Rica, periferia/centro, público/privado. ¿Cuándo?, presente/pasado, olvido/memoria. ¿Qué?, crimen-violencia. Por último, la más importante de todas: ¿quién soy?, solo se responde con una crisis de identidad.

\subsection{El cuadro final y la constitución panóptica de la novela}

El cuadro final de la novela puede ser tan clarificador del sentido de la misma como el cuadro inicial. En el caso de la novela Cruz de olvido, este elemento paratextual posee un condensado de sentido mayor, ya que, hasta en la última página, es la cruz la que establece las pautas espacio-temporales de este recorrido: arriba-bajo, abajo-arriba, atrás-adelante y adelanteatrás, que siempre termina uniéndose en el texto narrativo y en el acto de escritura. Asimismo, fragua el sentido inicial de la novela, en conjunto con los demás paratextos que la conforman.

En la última página de la novela de Cortés, la connotación de los demás paratextos (epígrafes, título principal, íncipit) develan el panoptismo de la cruz, por ende la representación del poder racional como elemento de coerción ideológica sobre el sujeto, mediante dos funciones básicas: vigilar y castigar a todo aquel individuo que no siga las pautas establecidas. Esta doble función, tal como lo plantea Michel Foucault, se representa en una arquitectura que no sólo sirve para ser vista, o para vigilar el espacio exterior, sino: “...para permitir un control interior, articulado y detallado - para hacer visibles a quienes se encuentran dentro [...] habría de ser un operador para la transformación de los individuos: obrar sobre aquellos a quienes abriga, permitir la presa sobre su conducta, conducir hasta ellos los efectos del poder, ofrecerles a un conocimiento, modificarlos" (1984: 177). Asimismo, se devela la manipulación en el ejercicio de este poder, que lleva a la anulación del sujeto hasta el olvido, como mecanismo de sujeción social, y donde la memoria es mortífera, pues involucra el cuestionamiento. Precisamente, el olvido se concibe como paliativo, en tanto que la memoria implica, respectivamente, reflexióncuestionamiento-crítica; en síntesis, se genera una crisis del sujeto (de sujetar) y de su identidad (de identificación social).

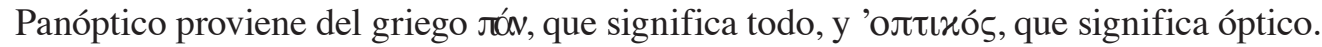
Se refiere al edificio construido de modo que toda su parte interior se pueda ver desde un solo punto (Diccionario de la Real Academia de la Lengua Española 1984: 970). En relación con la cruz que se erige en Alajuelita, en San José, la novela presenta este elemento como sinónimo 
de un panóptico. Esto se hace evidente en los últimos tres párrafos que constituyen el cuadro final de la novela.

\begin{abstract}
Algunas veces, en los días claros, cuando el aire es transparente casi se le puede tocar, saldrás de tu casa en Mata Redonda y señalarás con el dedo la montaña azul que tendrás enfrente... aunque todas las montañas son azules desde lejos... entonces te aclararás un poco más la vista... y fijarás minuciosamente el contorno casi esculpido sobre el cielo de la Cruz, allá a lo lejos. La recordarás muy bien porque cuando venías por la noche con tu madre, en las noches más oscuras, te servía de guía, la gigantesca cruz, iluminada y vigilante. Cuando dudabas de algún punto cardinal te bastaba con volver a verla y sabías: el sur. Te bastaba con eso. Ahora la miras con pavor. La señalarás con el dedo. Es inmensa y la podrás ver desde cualquier parte del Valle Central. Desde cualquier parte... como una imagen de tu tiempo...

Le pusieron iluminación en 1963, pero La Cruz es mucho, mucho más vieja... entonces, en un día claro, en un día absoluto, como los días que no existen desde que eras niño, cuando fuiste relativamente feliz, que es probablemente el rasgo más determinante de la felicidad, la verás de lejos y la señalarás con el dedo... afinarás tus ojos y lanzarás tu mirada hacia allá, hasta la montaña azul, aunque sabrás que todas las montañas son azules desde lejos, y si tenés suerte podrás ver lo que yo veo: una imagen de tu tiempo. Podrás ver cómo un hilillo de sangre va bajando desde la boca de la montaña, al pie de La Cruz, hasta la meseta...podrás reconocerlo por el color rojo escarlata, que brillará con el sol, a la luz del día. Y no sabrás por qué. Y le preguntarás a todos en el pueblo y ninguno se acordará, ni ninguno sabrá responderte. Y vos también, vos también, con el tiempo, que todo lo borra, que todo lo cura, lo bueno y lo malo, implacablemente, te olvidarás de todo, hasta de tu nombre (Cortés 2000: 344).
\end{abstract}

Carlos Cortés cierra la novela con una larga descripción de La Cruz de Alajuelita, la cual proyecta su imagen sobre el Valle Central, lugar donde se unificó el concepto metafísico de la identidad costarricense. Como valle, el espacio geográfico al que se alude aparece circunscrito por una serie de estribaciones montañosas lejanas, que rodean aún más el sitio referido, dándole una connotación de encierro. El espacio geográfico se transforma en espacio psicológico del encierro, en directa analogía con una cárcel de la cual no se puede salir, ya que la huida estará marcada por el inevitable retorno.

Unido a la delineación de un espacio psicológico del encierro, ubicado en el Valle Central, aparece la meticulosa descripción de la cruz. Algunos de los adjetivos que se le atribuyen a este elemento simbólico son: lejana, guía, vigilante, gigantesca, inmensa, iluminada, vieja; además, se sugieren otras características: "Cuando dudabas de algún punto cardinal te bastaba con volver a verla y sabías: el sur” (Cortés 2000: 344). Este símbolo se presenta como una especie de torre de vigilancia que se cierne sobre el Valle Central, y hace recordar el ejercicio del poder desde lo alto, casi como atribución divina: “...y fijarás minuciosamente el contorno casi esculpido sobre el cielo de La Cruz, allá a lo lejos” (Cortés 2000: 344). En este sentido, tal como lo indica Foucault, se produce el mayor efecto del panóptico: “...inducir en el detenido un estado consciente y permanente de visibilidad que garantiza el funcionamiento automático del poder. Hacer que la vigilancia sea permanente en sus efectos, incluso si es discontinua en su acción" (1984: 204).

El uso de la mayúscula en la escritura de este elemento connota algo más que la referencia a un lugar geográfico, pues la propia función de los adjetivos antes señalados, indica una personificación de La Cruz, como el cancerbero del centro-poder-opresor y tal como lo indica Eduardo Mendieta, se constituye en el lugar "desde donde algunos pueden ver sin ser vistos, y a otros ser vistos, pero no mirar [...] es un mecanismo que perpetúa el ejercicio del poder sin siquiera requerir de alguien que lo ejercite y despliegue" (1998: 247).

En consecuencia, el simbolismo de la manipulación y la enajenación del individuo se ostenta a través de la cruz-martirio, la cual sirve de parámetro para perpetuar las relaciones de poder, de ahí la asociación con el día y la noche. El día, asociado a la claridad absoluta y a 
la luz como símbolo de conocimiento, indica la conciencia del individuo de la existencia de la opresión. Por lo tanto, el acto de ver y/o mirar refieren al ojo, cuya simbología está asociada al sol: “...al ser el sol foco de luz (símbolo de inteligencia y espíritu) el acto de ver expresa acción espiritual y simboliza el comprender" (Cirlot 1969: 352). La noche, en oposición al día, representa la ignorancia y el desconocimiento, es el no-ver; por lo cual, la inmensa cruz iluminada del conocimiento racional y espiritual es la única guía en la oscuridad de la ignorancia heredada a través del concepto maternal: “...cuando venías por la noche con tu madre, en las noches más oscuras, te servía de guía...” (Cortés 2000: 344).

La descripción de la cruz como panóptico implica relaciones semánticas aún más importantes, ya que en palabras de Mendieta: “...la modernidad es un panóptico cuya torre es el ojo omnisciente del tiempo; es un mecanismo para la partición de cronometrar (temporalizar) y ser cronometrado (ser temporalizado)" (1998: 248). La cruz es un elemento permanente en la vida de los pobladores del Valle Central, atemporal, siempre ha estado ahí, es más vieja de lo que todos pueden recordar, de hecho es “...una imagen de tu tiempo...”. Esta frase recurrente en el cuadro final de la novela confirma las palabras de Mendieta, donde la cruz se vuelve el panóptico temporal de la modernidad. De tal manera, la relación entre panóptico y tiempo indica que el efecto disciplinario se vuelve bloqueo para: “...detener el mal, romper las comunicaciones, suspender el tiempo" (Foucault 1984: 212).

Estrictamente relacionados con el aspecto temporal de la cruz panóptica, los verbos empleados se pueden seccionar en los tres tiempos gramaticales: presente, pretérito y futuro; sin embargo, la fuerza del cuadro final está marcada en el futuro, al ser la forma temporal más recurrente.

Los verbos en pretérito aluden a la niñez, en tanto que los verbos en futuro remiten a la vida adulta. El aspecto de la duda se presenta en la infancia, pero no es sino hasta la vida adulta que el individuo empezará a plantear inquietudes más fuertes, es decir, a ser consciente, crítico y reflexivo. Sin embargo, los verbos futuros en negativo aluden a las acciones que no son realizadas, en tal caso el individuo no encuentra respuesta a sus interrogantes.

El cuadro final de la novela está narrado en forma de conversación, donde un yo, que aparenta ser el padre (Martín Amador), se dirige a un tú, que parece referir al hijo (Jaime); sin embargo, las narraciones sobre la infancia producen ambigüedad, ya que en realidad son menciones recurrentes del yo a sí mismo y sobre su propia vida. Por lo tanto, el texto es en realidad un monólogo interior, donde la mismidad-conciencia establece su propia claridad de visión acerca del proceso de dominación y control, que ejerce el centro-poder a través de ese elemento abstracto (identidad = identificación = pertenencia), representado en la cruzpanóptico del tiempo.

El efecto de controlar, de ver sin ser vistos, que proporciona una mayor fuerza al centropoder, se asocia con el efecto martirizante que es la cruz panóptica. En el último párrafo de la novela, la sangre como signo de muerte y sufrimiento, proviene de la cruz y brilla con el sol (luz $=$ conocimiento), pero nadie recuerda ni puede responder a las interrogantes que surgen. En consecuencia, el olvido borra toda duda o reflexión que pueda surgir en el individuo, anula la conciencia crítica y la capacidad de reacción; por estas razones, se transforma en el mecanismo de control social más efectivo y lacerante.

En último lugar, la frase que cierra el cuadro final de la novela alude al olvido del propio nombre del individuo: "Y vos también, vos también, con el tiempo, que todo lo borra, que todo lo cura, lo bueno y lo malo, implacablemente, te olvidarás de todo, hasta de tu 
nombre" (2000: 344). Es significativo recordar, tal como lo plantea Yadira Calvo Fajardo en su ensayo "La palabra crea objetos", que el nombre de las cosas posee la fuerza de darles existencia social e identidad, pues lo que no tiene nombre no existe. Por ende, el cierre de la novela se vuelve absolutamente significativo, ya que indica el olvido de la propia identidad del individuo, como un fenómeno colectivo en los pobladores del Valle Central. Esto genera la crisis de identidad en el narrador, quien confirma que esa anulación es mediante el tiempo, en su representación panóptica: La Cruz.

Cruz de olvido denuncia ese panóptico racional de la modernidad, en su forma más opresora: la manipulación a través del tiempo. La modernidad racionalizada encadena, mira, mide, encarcela con rejas imaginarias al individuo, sin posibilitarlo para destruir y construir y, finalmente, le anula su propia identidad.

\section{Conclusión}

La lectura paratextual de la novela Cruz de olvido, del escritor costarricense Carlos Cortés, permite observar las posibilidades de análisis y aplicación de este constructo teórico. Asimismo, el recorrido realizado a través del tejido del texto narrativo representa un acercamiento crítico al estudio específico de la literatura costarricense finisecular (fin de siglo XX y principios de siglo XXI), la cual se concibe como cuestionadora y crítica de sus propias circunstancias históricas, culturales y sociales.

Por su parte, los epígrafes y el título anuncian las críticas esenciales que originan el descontento y el tono amargo de toda la novela: la razón de la modernidad como elemento de opresión simbólica hacia el sujeto. En este sentido, la fuerza del título apoya el cuadro final de la novela, el cual es casi desesperanzador. Por su parte, el íncipit dibuja las fronteras espaciotiempo del panoptismo de la modernidad, desde donde se desarrolla el sentido crítico total del texto literario.

\section{Notas}

1. Joseph Roth nació en Galitzia en 1894 y murió en París en 1939. Periodista y escritor, entre sus textos destaca La marcha de la Radestzky, de 1932.

2. Francis Scott Fitzgerald nació Minesota en 1896 y murió en Hollywood en 1940. Entre sus novelas se encuentran: El gran Gatsby (1925), Suave es la noche (1934) y El último magnate (1941).

\section{Bibliografía}

Amoretti Hurtado, María. 1983. "Comenzar por el comienzo o la teoría de los íncipit”. Revista de Filología y Lingüística de la Universidad de Costa Rica. 9 (1): 145- 154.

Barthes, Roland. 1974. ¿Por dónde empezar? Francois Llinás (trad.). Barcelona: Ediciones Seuil y Tusquets.

Corominas, J. 1974. Diccionario crítico etimológico. Madrid: Editorial Gredos. 
Chaverri Fonseca, Amalia. 1987. "Algunos aspectos de titulogía novelística costarricense”. Káñina. 11 (1): 11- 37.

1987. "Relaciones intertitulares a partir de Retorno al Kilimanjaro". Revista de Filología y Lingüística de la Universidad de Costa Rica. 17 (1- 2): 21- 27.

1997. Asalto al paraíso: Una transmetáfora que rescribe la historia. Tesis para optar al grado de Magister Literarum en Literatura Latinoamericana. San José, Universidad de Costa Rica.

Cirlot, Juan Eduardo. 1969. Diccionario de símbolos. Barcelona: Editorial Labor.

Cortés Zúñiga, Carlos. 2000. Cruz de olvido. San José: Editorial Alfaguara.

Ediciones Larousse. 2002. Diccionario Pequeño Larousse Ilustrado. Barcelona: Editorial SPES.

Foucault, Michel. 1984. Vigilar y castigar (Nacimiento de la prisión). 9a ed. México: Editorial Siglo XXI.

Genette, Gérard. 1987. Seuils. París: Ediciones Du Suil.

1989. Palimpsestos. Celia Fernández Prieto (trad.). Madrid: Editorial Taurus.

Greimas, A. J. y J. Courtés. 1990. Semiótica. Diccionario razonado de la teoría del lenguaje. Madrid: Editorial Gredos.

Mendieta, Eduardo. 1998. "La geografía de la utopía: Regímenes espacio-temporales de la modernidad". Cuadernos Americanos. 1 (67) (ene- feb): 238- 255.

Real Academina Española. 1984. Diccionario de la Real Academia de la Lengua. $20^{\mathrm{a}}$ ed. Madrid, España: Editorial Espasa-Calpe. 